\title{
MEDIOS DE COMUNICACIÓN Y GESTIÓN DEL CONOCIMIENTO
}

\author{
Mar de Fontcuberta $(*)$
}

SÍNTESIS: Las claves para el análisis de la relación entre la educación y los medios parecen ocultarse en las respuestas a algunas preguntas significativas: ¿Qué significa hoy conocer? ¿Qué significa gestionar el conocimiento? ¿Están los padres, las familias y los profesores preparados para ser unos mediadores competentes que hagan posible que los niños puedan aprovechar al máximo las posibilidades que ofrecen los medios?

La educación necesita dar respuesta a los desafíos que surgen: las nuevas formas de conocer; la creciente complejidad social, caracterizada por la contradicción y la incertidumbre; la globalización y la cultura mediática con las que debe compartir su espacio tradicional.

Mientras que la tradición escolar ha identificado el conocimiento con la acumulación de saberes ordenados, clasificados y jerarquizados, hoy sabemos que el conocimiento se construye individualmente, que el aprendizaje es una actividad intencional, y que, por tanto, depende de la voluntad y de la predisposición para participar del proceso de enseñanza-aprendizaje.

La revisión de los conceptos de enseñanza como mera transmisión de conocimientos, y de aprendizaje como receptividad pasiva de la información transmitida, propone la aparición de la idea de gestión del conocimiento, entendida en el sentido de saber cómo acceder a las informaciones necesarias, seleccionarlas, articularlas y aplicarlas a un determinado objetivo.

Tal definición lleva implícito el nuevo papel que los medios están jugando en la educación, convirtiéndose, de transmisores de información, en contenedores de una parte de los conocimientos. Ese nuevo rol no es una disfunción del proceso educativo, sino un síntoma del cambio de ese proceso.

El desafío al que comunicadores y educadores deben hacer frente es al del atrincheramiento en miedos y prejuicios. La integración de los medios como parte del proceso de enseñanza-aprendizaje y el análisis conjunto de las cuestiones que tienen que ver con la formación de los ciudadanos, pueden ser la vía de superación de estériles y obsoletos desencuentros.

ca, Chile.

(*) Directora del Magíster en Comunicación y Educación, Universidad Católi- 
SÍNTESE: As chaves para a análise da relação entre a educação e os meios parecem ocultar-se nas respostas para algumas perguntas significativas: O que significa, hoje, conhecer? O que significa administrar o conhecimento? Estão os pais, as famílias e os professores preparados para ser mediadores competentes que tornem possível que as crianças possam aproveitar ao máximo as possibilidades que os meios oferecem?

A educação necessita dar resposta aos desafios que surgem: as novas formas de conhecer; a crescente complexidade social, caracterizada pela contradição e pela incerteza; a globalização e a cultura midiática com as quais deve compartilhar seu espaço tradicional.

Enquanto a tradição escolar tem identificado o conhecimento com o acúmulo de saberes ordenados, classificados e hierarquizados, hoje sabemos que o conhecimento se constrói individualmente, que a aprendizagem é uma atividade intencional, e que, portanto, depende da vontade e da predisposição para participar do processo de ensino-aprendizagem.

A revisão dos conceitos de ensino como mera transmissão de conhecimentos, e de aprendizagem como receptividade passiva da informação transmitida, propõe a criação da idéia de gestão do conhecimento, entendida no sentido de saber como ter acesso às informações necessárias, selecioná-las, articulá-las e aplicá-las a um determinado objetivo.

Tal definição leva implícito o novo papel que os meios estão tendo na educação, convertendo-se, de transmissores de informação, em armazenadores de uma parte dos conhecimentos. Esse novo papel não é uma disfunção do processo educacional, mas, sim, um sintoma da transformação desse processo.

$O$ desafio a que comunicadores e educadores devem fazer frente é o do entrincheiramento em medos e preconceitos. A integração dos meios como parte do processo de ensino-aprendizagem e a análise conjunta das questões que têm a ver com a formação dos cidadãos podem ser a via de superação de estéreis e obsoletos desencontros.

\section{INTRODUCCIÓN}

La educación del siglo XXI quizás se enfrenta a los desafíos más importantes que ha tenido la humanidad desde la invención de la imprenta. Son varios los factores que los determinan: la necesidad de un cambio educativo ante un nuevo modo de conocer; las exigencias de una sociedad compleja, en la que los fenómenos sociales están cada vez más interrelacionados y que deben aceptar la contradicción y la incertidumbre como métodos de acceso al conocimiento; la globalización; y la existencia de una cultura mediática que ha ocupado espacios hasta 
hace poco reservados al sistema educativo. La solución a tales desafíos es una tarea crucial para el futuro de nuestras sociedades.

Como afirma Goéry Délacôte ${ }^{1}$, hay tres grandes revoluciones en marcha que provocan el gran cambio educativo: la de la interactividad, la cognitiva y la de la gestión de los sistemas educativos. Afirma que ellas modifican el acto de aprender, su comprensión, su dinámica individual, las organizaciones sociales y técnicas que la sostienen, y su gestión personal y colectiva.

La aparición de los sistemas multimedia ha propiciado la primera de las revoluciones, al reconfigurar los roles y al establecer nuevas relaciones entre emisor/receptor, narrador/lector, profesor/alumno. «Es importante señalar aquí la aplicación de una característica fundamental de estos nuevos instrumentos multimedia: la transferencia al lector de lo que en medios tradicionales corresponde al narrador. En efecto, es el usuario quien construye el relato que ningún narrador habrá elaborado completamente. El papel de quien concibe el programa es suministrar las piezas fundamentales de los relatos [...]. Al hacerlo, el usuario habrá de construir por sí mismo una historia que, para resultar sensata y formar un relato coherente, exige que el lector salga en busca de conocimientos, los utilice y los consolide. El saber del usuario ya no será el resultado del relato que se le presenta, sino que él mismo lo irá construyendo mientras elabora la narración $»^{2}$. Eso lleva a una modificación en la función del educador, ya que los maestros cambiarán su papel de creadores de productos para la red por el de facilitadores y de guías del uso de los recursos que ofrece dicha red. Asimismo, el alumno debe abandonar la actitud de receptor pasivo de contenidos educativos suministrados por el profesor, para convertirse en protagonista activo de su adquisición de conocimientos.

La segunda de las revoluciones es la cognitiva. Delacôte plantea una idea clave: hay que dar prioridad al desarrollo de las aptitudes cognitivas de orden superior de los que aprenden. Estas aptitudes pueden agruparse en tres grandes categorías: el conocimiento profundizado

1 Goéry Délacôte es físico y fue director del Departamento de Comunicación del Centre National de Recherche en Sciences Sociales de París y cofundador del Museo de Ciencias La Villette. Dirige uno de los museos científicos más prestigiosos del mundo, el Exploratorium de San Francisco, EE.UU.

2 G. Delacôte (1997): Enseñar y aprender con nuevos métodos. La revolución cultural de la era electrónica, Barcelona, Gedisa, p. 32. 
de cierta esfera del saber, la comprensión de las condiciones en las cuales se puede utilizar ese saber, y, por fin, la facultad de control y de dirección metacognitiva. «Es decir, la enseñanza debe tener un contenido, el saber debe poder utilizarse para resolver problemas incluso en situaciones nuevas no exploradas, y, por último, un individuo debe tener el control consciente y voluntario de sus propios procesos cognitivos, de sus razonamientos, de la manera en que aprende, de lo que ocurre en su memoria y del modo en que puede robustecer su funcionamiento para mejorar los resultados»3. La tercera de las revoluciones está propiciada por las dos anteriores, y es la que exige un cambio en la gestión de los sistemas educativos.

Aunque hoy nadie discute que nos hallamos en la sociedad del conocimiento, podemos encontrar serias divergencias a la hora de analizar y de evaluar sus características. La complejidad que implica un concepto tan profundo y dinámico como «sociedad del conocimiento» ha entrado en conflicto con un sistema educativo anclado en otros parámetros. En efecto, la tradición escolar y universitaria ha identificado el conocimiento como la acumulación de saberes ordenados, clasificados y jerarquizados. De acuerdo con ella, el alumno debe recorrer con esfuerzo un camino en el que va a adquirir sucesivamente, es decir, de modo secuencial, una serie de conocimientos impartidos por varios profesores en un espacio determinado (aula), que seguirán sus respectivos programas según un diseño curricular, que, una vez superadas las distintas pruebas establecidas al efecto, le conducirán a la obtención de un título reconocido que le identificará como experto en un ámbito determinado del saber.

Sin embargo, esa tradición se encuentra en crisis. Pérez Tornero señala varias claves que la definen:

- Crisis en los currículos escolares. La producción del saber es tan intensa y circula tan rápido por todos los medios, sobre todo los electrónicos, que no se sabe cuál es el modo más práctico y seguro de fijar los ítems que compondrán la práctica docente.

- Crisis en el rol del profesorado. De tradicionales transmisores del saber, en medio de un mundo que genera nuevos saberes fuera de las aulas, los profesores y las profesoras 
ven cómo van perdiendo la función para la que se formaron y empiezan a verse sometidos a nuevas exigencias y requerimientos que muchas veces no comprenden o no desean asumir.

- Crisis en el lenguaje que funda la escuela. Su escriturocentrismo tradicional resiste con poca convicción la preponderancia de los nuevos lenguajes audiovisuales y la informática.

- Crisis de recursos técnicos. Comparadas con el entorno inmediato, las escuelas se han quedado desfasadas en su tecnología, incluso en el mundo industrial más avanzado.

- Crisis de valores y de sistemas de socialización. Una escuela fundada en la pura tradición burguesa, es decir, centralizada, casi siempre nacionalista, asistencial y fabril, se encuentra abocada a sobrevivir en una sociedad postindustrial, globalizada y multicultural.

- Crisis de gestión. Se están quedando obsoletos los modelos de organización y de gobierno basados en el control estricto del aprendizaje y en su dirección lineal, en la comunicación jerárquica, en la evaluación ajustada a criterios de repetición, y, en general, en la burocratización, ocupada más en la reproducción de lo existente que en la adaptación a los cambios, en la innovación o en la creación ${ }^{4}$.

Situados en ese contexto, la pregunta fundamental es: ¿qué significa hoy en día conocer? Parece claro que algo distinto a lo que se ha considerado hasta hace poco tiempo. Actualmente es imposible almacenar de forma permanente un acervo de conocimientos para toda la vida. La cantidad de información es tan impresionante como el poco tiempo que tarda en quedar superada. Eso queda patente en la necesidad de especialización y de profundización en un campo específico por parte de personas que desarrollan su actividad en el mundo profesional, y que requieren una continua puesta al día de conocimientos aplicados. También ha aumentado la demanda de formación en nuevas disciplinas en el ámbito académico y profesional, y la necesidad de establecer objetos de estudio desde una perspectiva transdisciplinaria.

4 J. M. Pérez Tornero (2000): «Las escuelas y la enseñanza en la sociedad de la información», en Comunicación y educación en la sociedad de la información, BarceIona, pp. 49-50. 
La irrupción de los sistemas multimedia y su progresiva implantación suponen un cambio fundamental en los ámbitos laboral y educativo. En el primero, cada vez es más común la figura del profesional que trabaja desde su casa conectado a un ordenador, sin necesidad de desplazarse a una oficina. «Estar presente» en el centro de trabajo ya no es fundamental para muchas profesiones, pero sí lo es la productividad y la toma de decisiones tanto individuales como en equipo. El cambio se extiende también, progresivamente, al sistema educativo. La oferta docente se flexibiliza. Los estudiantes de una misma carrera muchas veces no tienen los mismos objetivos, y seleccionan sus programas de estudio de acuerdo con sus intereses específicos a través de diversos itinerarios. Tampoco aquí la presencia continua es indispensable. Hay universidades que ofrecen estudios que combinan la docencia presencial con el aprendizaje a través de redes. Como ya hemos dicho, los multimedia reconfiguran el modelo del alumno, del profesor y de todo el proceso del conocimiento. Ya no hay secuencialidad, ni un lugar central del que depende la información, ni un solo emisor. El único eje vertebrador es la voluntad del usuario, sus propios intereses. Por eso la enseñanza debe cambiar: la reproducción, la memorización y el almacenamiento del saber han de sustituirse por la capacidad de buscar la información y de seleccionar los contenidos necesarios para la formación requerida.

Ese nuevo modo de acceder al conocimiento pone en cuestión gran parte de las bases sobre las que se ha asentado muestro sistema educativo. Para empezar, ha entrado en crisis la idea de que existe un saber constituido, y que basta la transmisión de la información de profesor a alumno para que tenga sentido la enseñanza. Sabemos que el conocimiento se construye individualmente y que la información no tiene sentido para una persona si no está predispuesta a recibirla y a integrarla en su propia red de experiencias cognitivas. Esa predisposición es muy importante para la distinción de los conceptos de enseñanza y aprendizaje, ya que este último se define por una característica clave: es una actividad intencional. La autonomía del aprendizaje se define como «la capacidad del alumno para escoger y para utilizar por sí mismo los recursos puestos a su disposición con el fin de definir su proyecto, de trazar su itinerario, de apropiarse del saber y del saber-hacer y de evaluar sus conocimientos adquiridos» ${ }^{5}$. En el aprendizaje el alumno decide sus objetivos y los caminos para lograrlos mediante iniciativas

5 M. Linard (1991): "Médiation technique et médiation humaine», en La formation multimédia. Apprendre et former autrement, Collection IDATE, Synapse, p. 27. 
propias, mientras que en la enseñanza es el profesor quien establece las pautas de acceso al conocimiento. Por desgracia ambos conceptos se han visto enfrentados en la práctica, ya que las libres iniciativas de los alumnos (aprendizaje) han sido contempladas como una distorsión, o incluso como una amenaza para los conocimientos impartidos por el profesor (enseñanza).

En muchas ocasiones, el mundo escolar y académico ha reaccionado con desconfianza ante el nuevo panorama educativo. Considera que promover el aprendizaje potenciado por la irrupción de los multimedia lleva a la adquisición de un conocimiento fragmentado y disperso, sin bases sólidas, que tiene como resultado la pérdida de sentido. Me gustaría apuntar dos ideas: quienes critican lo hacen a menudo desde una sospechosa actitud patrimonialista del saber, olvidando las enormes parcelas de conocimiento que han sido ignoradas a través de la historia por la aplicación de cánones académicos que tenían más contacto con intereses de determinados sectores sociales que con una actitud realmente científica. Por otra parte, señalar la importancia del proceso de aprendizaje no significa eliminar el proceso de enseñanza, sino poner de relieve que ésta debe cambiar de método para conseguir que ambos sean complementarios. En la adecuada resolución de los procesos de enseñanza y aprendizaje reside el éxito de la formación de las futuras generaciones ${ }^{6}$. Hasta tal punto eso es cierto, que, desde el campo de la Psicología de la Educación, se ha llegado a afirmar que «los pobres y los marginados del siglo XXI serán aquellos que no puedan o no sepan comprometerse con el aprendizaje durante toda la vida» ${ }^{7}$. Un aprendizaje que va mucho más allá de las disciplinas que se imparten en escuelas o en universidades. «Ciertamente, cuando leemos un manual o vemos las noticias, acumulamos datos e información. Y este conocimiento lo ordenamos en opiniones. Pero también continuamos durante toda la vida desarrollando destrezas: cómo utilizar las nuevas tecnologías, cómo montar en bicicleta, cómo preparar un soufflé, como narrar una buena historia, cómo escribir, cómo tocar la trompeta. Aprendemos a hacer nuevas diferenciaciones: a adivinar el estado de ánimo de un nuevo amigo por su tono de voz al teléfono, a distinguir un burdeos de un borgoña, a distinguir a Brahms de

6 Parte de esos aspectos está publicada por mi en «Medios, comunicación humana y sociedad del conocimiento», en Comunicar, núm. 14, año 2000, Huelva, Grupo Comunicar, p. 27.

7 La afirmación corresponde a Guy Claxton, director de la Research Initiative on Culture and Learning in Organisations de la Universidad de Bristol (Gran Bretaña) en su obra Aprender. El reto del aprendizaje continuo (2001), Barcelona, Paidós, p. 277. 
Mendelssohn. Aprendemos nuevas preferencias: lo que nos gusta y lo que nos disgusta cambia a medida que crecemos y que tenemos nuevas compañías. Una bebida que en un tiempo parecía peculiar o desagradable se convierte en un gusto adquirido. Desarrollamos nuevas disposiciones: la tendencia a no reírse de chistes que en su tiempo fueron divertidos pero que ahora nos parecen burdos o crueles, a tener más tiempo para personas que antes nos impacientaban. Aprendemos roles y nuevos aspectos de nuestro carácter. Descubrimos lo que significa ser una chica, ser un abuelo, un profesor, un aficionado al fútbol, alguien aquejado de migrañas, y a actuar en consecuencia. Podemos ampliar nuestro abanico emocional y aprender cuándo y cómo expresar indignación o simpatía. El aprendizaje cambia no sólo nuestro conocimiento y nuestro hacer, sino también nuestro ser»8.

\section{DE LA TRANSMISIÓN DE CONOCIMIENTOS A LA GESTIÓN DEL CONOCIMIENTO}

De acuerdo con todo lo anterior, los desafíos que deben afrontarse en la educación del siglo xxı pasan por un cambio de mentalidad y de actitud tanto en los alumnos como en los profesores. Frente a la identificación tradicional de la educación como transmisión de conocimientos, se impone un nuevo concepto: el de la gestión del conocimiento.

Pero ¿qué significa gestionar el conocimiento? En principio, saber cómo acceder a las informaciones, seleccionarlas, articularlas y aplicarlas a un determinado objetivo. El sistema económico y social plantea nuevas necesidades a las que debe dar respuesta el sistema educativo, y una de las más importantes es la de educar a ciudadanos capaces de organizar su propia formación. Robert Kegan, pedagogo de la Universidad de Harvard y citado por Claxton, describe la situación actual como una transición que conduce de lo que llama una cultura «automática» a una cultura "manual». En una cultura automática, las reglas y los rituales aceptados y las ideas de la sociedad funcionan como la caja automática de cambios de un coche. Cuando alcanzamos determinada velocidad, el coche «decide» cambiar la marcha. Nosotros, los conductores, no tenemos que pensar en ello. No tenemos el control, lo tiene el coche. En una sociedad homogénea, tradicional, estable, no tenemos la responsabilidad individual de decidir lo que significa la tran-

8 Id., pp. 219-220. 
sición de niña a mujer, de soltero a casado, o a padres; tampoco, en gran medida, cuándo y cómo hacer esa transición. Lo que es normal, lo que es repugnante, lo que es admirable, lo que es una diversión inofensiva, lo que es sugerente, lo que viene a continuación; estos juicios están hechos, son incuestionables; forman parte de la maquinaria por la que uno vive, no son objeto de escrutinio o de error. Pero en una cultura manual, como en un coche con cambio de marchas normal, uno tiene la responsabilidad de decidir. "En estas sociedades tenemos que tener las habilidades y tolerancias que el ciudadano "automático" simplemente no necesita, y, por lo tanto, no echa de menos. Necesitamos ser capaces de manejar con inteligencia unos niveles de responsabilidad y de incertidumbre mucho mayores. Precisamos ser unos buenos aprendices» 9 .

Si un buen aprendiz necesita tomar decisiones, debe tener acceso a la información requerida para ser capaz de analizar las diferencias entre las distintas opciones que se le presenten. Y esa información no sólo se encuentra en los libros o en la experiencia académica. Hoy gran parte de esos conocimientos no se transmite en las aulas sino que circula por los medios de comunicación. Tanto en el proceso de adquisición y transmisión de información como de conocimientos los medios juegan un papel fundamental, hasta el punto de que se instituyen en referentes esenciales en el ámbito educativo a la hora de obtener una determinada conceptualización del mundo. Se han convertido en vehículos básicos y en los principales impulsores de circulación del conocimiento, y, por ello, son un referente imprescindible en la educación no formal a la hora de seguir nuestras pautas culturales. El ciudadano actual convive con ellos y los tiene como punto cardinal de referencia. La gente habla y opina de los temas que se tratan en la radio, en la televisión, en la prensa o en Internet, e ignora los acontecimientos sucedidos en un entorno próximo, que no tienen cobertura noticiosa o de entretenimiento. Queramos o no, somos seres mediáticos y pertenecemos a una cultura que no puede entenderse y que tampoco existe al margen de la comunicación.

Aunque la comunicación y la educación son conceptos estrechamente vinculados, la relación ha sido conflictiva. Se ha producido un desencuentro entre medios y escuela (que empieza a superarse en algunos contextos), lo que supone también, como ya vimos, un desencuentro entre el binomio enseñanza/aprendizaje. Desde el campo edu-

9 Robert Kegan, (1992): In Over our Heads: the Mental Demands of Modern Life, Cambridge, Harvard University Press. Citado por Claxton, p. 275. 
cativo, los medios fueron vistos como una amenaza a la acción de la escuela y de la familia, o, en el mejor de los casos, como un estorbo. Su influencia generó diversos movimientos de alarma social, que, desde perspectivas diferentes, estimaron que había que hacer frente a una situación que se consideró en general perniciosa para niños y jóvenes. Tanto desde el ámbito de la investigación como desde la práctica cotidiana, estudiosos y educadores desarrollaron «respuestas antídoto» que fueron desde transmitir una visión apocalíptica de los medios en las aulas hasta la prohibición de ver televisión en el hogar o de navegar por Internet, por ser factores que distorsionaban los valores de la educación.

Contemplar los medios como una distorsión del desarrollo educativo provocó un debate estéril entre educadores y comunicadores -que todavía se arrastra-, y que ha desviado la atención del problema: el nuevo rol de los medios de comunicación no es una disfunción del proceso educativo, sino un síntoma de cambio de ese proceso. El cambio se debe a que nos hallamos en una sociedad en la que el conocimiento se encuentra en todas partes, hecho que no siempre ha sido asumido por el sistema educativo. Martín-Barbero afirma que hay diferentes «destiempos en la educación»: de tipo socioeconómico, de desniveles tecnológicos, de los modelos de comunicación que subyacen en la educación, y afirma que las escuelas siguen fijadas en esquemas ya superados. Considera que hay un cierto desordenamiento cultural, según el clásico concepto de cultura, en el que hay una generación que no se construye a partir de identificaciones con figuras, estilos o prácticas, sino a partir de la conexión/desconexión con los aparatos. Ese desorden plantea desafíos a la familia y a la escuela. La familia no se da cuenta del verdadero papel que la TV está teniendo en la reconfiguración del hogar: la TV desordena las secuencias del aprendizaje, desvela el mundo real de los adultos y pone fin a la separación social entre ellos y los niños. Martin-Barbero introduce el concepto de "pensamiento visual» para reivindicar a la imagen como productora de conocimiento, y afirma que estamos ante el surgimiento de "otra forma de razón» en la que los medios juegan un papel decisivo porque designan un nuevo "sensorium" (W. Benjamin): nuevas posibilidades, otros modos de percibir, de sentir y de relacionarse con el tiempo y el espacio, nuevas formas de reconocerse y de juntarse. "Los medios significan para la escuela un reto cultural que hace visible la brecha cada día más ancha entre la cultura desde la que enseñan los maestros y aquella otra desde la que aprenden los alumnos. Los medios constituyen un decisivo ámbito de socialización, de dispositivos de identificación/proyección de pautas de com- 
portamiento, estilos de vida y patrones de gusto [...]. La escuela debe interactuar con los campos de experiencia en que hoy se procesan los cambios: desterritorialización/relocalización de las identidades, hibridaciones de la ciencia y del arte, de las literaturas escritas y las audiovisuales, reorganización de los saberes, desde los flujos y redes por los que hoy se moviliza no sólo la información, sino el trabajo y la creatividad, el intercambio y la puesta en común de proyectos, de investigaciones, de experimentaciones estéticas» ${ }^{10}$.

Pérez Tornero también se refiere al desencuentro entre educación y comunicación mediática, al afirmar que cuando diseñamos las instituciones y los métodos que se han de relacionar con el cultivo de la inteligencia -sobre todo los sistemas de enseñanza- lo seguimos haciendo en términos de unas tradiciones comunicativas que estaban abrumadoramente en una sola dimensión de la capacidad lingüística: la relacionada con el lenguaje verbal, denominado muchas veces lenguaje natural. Sobre esa base se han desarrollado los currículos escolares en sus diferentes niveles. Sin embargo, el análisis mediático no puede pasar por alto lo físico del medio, su realidad material. No puede olvidar que un medio de comunicación, en su realidad más concreta, condiciona el comportamiento del comunicador y del receptor. La televisión, por ejemplo, no es sólo transmisora de imágenes; es un dispositivo que sujeta al individuo delante de la pantalla, que le impone cierta inmovilidad corporal, que potencia unos sentidos en detrimento de otros. Las pantallas son hoy el germen de una especie de burbuja invisible, que no sólo amplía la transmisión de la información sino que está organizando y pautando la acción social. El sistema educativo debería asumir tal situación, pero no es así. "Nuestras prácticas comunicativas actuales van muy por delante de nuestros sistemas reflexivos de lenguaje dominantes en la enseñanza. Estamos respondiendo a situaciones nuevas con lógicas de otra época [...]. Una de las mayores barreras para el desarrollo de la inteligencia colectiva en la actualidad es el desfase existente en la educación entre un mundo ampliamente mediático y unas disciplinas demasiado tradicionales. Ello se revela en los planes de estudio, en los procesos pedagógicos y en la actitud de muchos profesores»11. De la misma opinión es Fuenzalida, quien tras dar a conocer una investigación llevada a cabo en Chile sobre el consumo y las motivaciones de los niños ante la televisión abierta, constató

10 J. Martín-Barbero (1998): «Heredando el futuro. Pensar la educación desde la comunicación», en Revista C\&E, Cultura y Educación, núm. 9. p. 29.

11 Pérez Tornero, op. cit., p. 96. 
que «el consumo televisivo y las motivaciones del niño y del joven televidente ante la TV revelan sujetos activos con intereses diversos y muy amplios, ante los cuales el Puer instruendus de la escuela aparece como un reduccionismo. Ante la TV el niño ha conquistado un enorme campo de libertad para elegir respuestas a sus motivaciones; las nuevas tecnologías electrónicas -como Internet- van a ampliar aún más estas elecciones activas» 12 .

De acuerdo con lo anterior, los medios no sólo son hoy vehículos fundamentales de acceso al conocimiento, sino que contienen parte de ese conocimiento que se caracteriza, como ya he afirmado en otras ocasiones, por su vinculación a la actualidad, por su transmisión a través de diferentes códigos, lenguajes y soportes, que, además de las respuestas lógicas, estimulan las sensaciones y proporcionan una oferta plural, en cantidad (y no siempre en calidad) de sus contenidos, que responde a criterios distintos y a veces enfrentados.

El tipo de conocimiento que se ofrece sin tiempo para analizarlo, pero que describe un contexto social cercano que mezcla emociones, sensaciones y razonamientos, que llega al receptor desestructurado y atomizado, coexiste conflictivamente con el que se imparte en general en las aulas, descontextualizado, unívoco, esquematizado y ordenado en parcelas estancas según cada disciplina. Ese es el desafío al que nos enfrentamos tanto los que trabajamos en comunicación como los que lo hacemos en educación: complementarlos.

\section{LOS MEDIOS, PUENTE ENTRE LA ENSEÑANZA Y EL APRENDIZAJE}

Los medios de comunicación se mueven entre los ámbitos de la enseñanza y el aprendizaje, y una utilización adecuada de sus recursos en el sistema educativo puede establecer un puente entre ambas nociones. Nos ofrecen toda una gama de posibilidades en ese campo. Por dicho puente transitan medios que tienen más contacto o están más cercanos al concepto de la enseñanza (como la prensa, que es el más reglado, el menos mutable y el que necesita de una serie de indicaciones del profesor para motivar para su uso), hasta el fenómeno de Internet o los multimedia, donde el acento recae casi en su totalidad en el

12 V. Fuenzalida (1999): "Consumo y motivaciones de los niños ante la televisión abierta», en Ramón Fiorenzano y Jorge Molina (eds.): Televisión y niños, Corporación de Promoción Universitaria, Televisión Nacional de Chile, p. 19. 
alumno, ya que los mecanismos que le impulsan a usar el medio están más cerca del aprendizaje.

En el caso de la prensa, el estudiante, en su inmensa mayoría, llega al aula sin el hábito de leer periódicos. Por lo tanto, deberá acostumbrarse a su uso en la escuela y es allí donde se inicia el proceso de enseñanza (que gira sobre el profesor en primer término), para ir desarroIlando el concepto de aprendizaje (que gira en torno al alumno). La prensa puede ser una buena herramienta para establecer estrategias de aprendizaje, siempre que el profesor conozca y sea capaz de analizar de forma pertinente sus contenidos. La edición de un periódico (sea en soporte papel o en versión electrónica) tiene muchísimos puntos de contacto con los mecanismos de aprendizaje: enfrentarse a un volumen ingente de información; tener que valorarla, seleccionarla, jerarquizarla, estructurarla y aplicarla. Conocer los mecanismos de la edición periodística, saber cómo analizarlos y evaluarlos críticamente y cómo convertirlos en acceso a la información, puede convertirlos en valiosos auxiliares para obtener conocimientos, para saber cómo obtenerlos, para valorarlos críticamente; y para gestionarlos adecuadamente con el fin de aplicarlos a un propósito determinado.

Sin embargo, en el caso de la televisión el proceso es inverso. El acceso al medio por parte del alumno se inicia antes de su llegada a la escuela y no necesita de estímulos para su uso. Dado que su relación con el medio se mueve en un ámbito mucho más perceptivo, la tarea del educador es hacerle reflexionar sobre sus contenidos.

En resumen, se trata de entender a los medios como espacios donde se produce conocimiento y se accede a éste, como herramientas de enseñanza y aprendizaje y como ámbitos de crítica y de intervención social.

\section{EL MIEDO A LOS MEDIOS}

No obstante, como se ha visto, la relación entre medios y educación no ha sido armoniosa. El conflicto entre comunicadores (entendiendo como tales a quienes analizan la comunicación mediática, no a quienes la producen) y educadores ha tenido, paradójicamente, puntos de acuerdo en muchas ocasiones: uno de ellos es la suspicacia frente a los medios; otro, considerar al receptor como un sujeto al que había que defender de su influencia. Si se analizan las diferentes teorías que han 
relacionado la comunicación y la educación, nos encontramos con que gran parte adopta una actitud beligerante. Martínez de Toda ha realizado un valioso trabajo de síntesis de los diferentes enfoques teórico/prácticos a lo largo de la historia, y ha llegado a la conclusión de que tienen como objetivo formar receptores en las siguientes dimensiones: sujeto alfabetizado mediáticamente, consciente, activo, crítico, social y creativo. Aunque considera que son dimensiones complementarias, advierte que no opinan lo mismo las distintas escuelas de pensamiento que los sustentan y que tienden a considerar los diversos enfoques como alternativos o como competitivos ${ }^{13}$.

Tres de los enfoques tienen en sus orígenes una actitud defensiva frente a los medios, y son los que han tenido más repercusión en el sistema educativo a la hora de generar actitudes docentes y propuestas pedagógicas. El sujeto alfabetizado mediáticamente se basa en las teorías que concebían la educación como transmitir cultura desde-a. La educación no se daba conforme a la vida como es sino como debería ser, y la misión del educador era transmitir la cultura y formar ciudadanos dentro de los valores culturales de su propia sociedad. Ello implicaba un desprecio a la cultura popular. El sujeto consciente surge del miedo a la supuesta influencia negativa de los medios. Les atribuye casi siepre el aumento de la violencia, el crimen y el abuso del sexo, y considera que la educación debe formar individuos capaces de discriminar los productos mediáticos que contengan lo que consideran actitudes antisociales El sujeto crítico es el resultado de las teorías que consideran que los medios son agentes de una ideología dominante, que benefician a los poderosos, que son manipuladores y que se imponen a un receptor pasivo por medio de la alienación. Es cierto que todos los enfoques han sido matizados después, pero subyace en todos ellos la consideración de que el receptor es un ser con una actitud pasiva frente a los medios, y, por lo tanto, permeable a sus influencias.

Las otras tres dimensiones parten del supuesto de que el receptor reacciona ante los mensajes de los medios de forma diferente de acuerdo con su contexto, su identidad, sus expectativas y sus necesidades. El sujeto activo es un deconstructor/reconstuctor del significado de los medios, es capaz de reflexionar críticamente sobre ellos, pero al mismo tiempo le entretienen y le ofrecen soluciones a sus problemas.

13 J. Martínez de Toda (1998): Metodología evaluativa de la educación para los medios: su aplicación con un instrumento multidimensional, Roma. Facultad de Ciencias Sociales, Universidad Gregoriana. 
Un paso más adelante hallamos al sujeto creativo, que no sólo es capaz de apropiarse del contenido de los medios de forma activa, sino que puede producir mensajes alternativos de acuerdo con los intereses de su propia cultura. Por último, hallamos al sujeto social, que sabe que en su concepción del mundo influyen diferentes mediaciones (familia, escuela, medios, etc.), que es interactivo con los demás, trabaja en grupo y utiliza los medios como un foro para intercambiar y discutir opiniones.

Hay que señalar que las tres últimas dimensiones han tenido un mayor desarrollo en los tiempos más recientes. Parece claro que, aunque todos los enfoques pueden ser complementarios, cualquier propuesta que pase por articular los espacios de la comunicación y de la educación ha de basarse en la concepción del receptor activo.

\section{UN EJEMPLO PRÁCTICO: VIOLENCIA Y MEDIOS DE COMUNICACIÓN}

Un ejemplo práctico de la distorsión que ha provocado el miedo a los medios en el ámbito educativo lo constituye la constante acusación que los vincula con la violencia social. La relación entre medios y violencia es de los temas más conflictivos en las relaciones entre comunicación y educación. Una de las tareas más arduas e inútiles que puede emprender cualquier investigador es cuantificar el número de congresos, seminarios, jornadas, artículos, libros y conferencias que se dedican anualmente al tema de la violencia en los medios. Si se aventura a navegar por buscadores especializados y pretende extraer conclusiones de tipo cualitativo, la pesadilla está garantizada: terminará abrumado por una ingente cascada de datos basados en cientos de estudios, que en nombre de la ciencia suelen anatematizar a los medios como causantes de gran parte de la violencia que invade la sociedad ${ }^{14}$.

Nadie duda de que la investigación sobre el contenido de violencia en los medios, y en particular en la televisión (siempre que com-

14 Estados Unidos lidera esta postura apocalíptica frente a los medios. Un ejemplo tipo es el artículo publicado en Science Magazine, vol. 295 (29 de marzo de 2002) por el profesor Jeffrey Johnson, en el que da cuenta de los resultados de una investigación realizada a lo largo de 17 años en una muestra de 707 personas. Los resultados mostrarían, según el investigador, una asociación significativa entre el tiempo utilizado en ver TV durante la adolescencia y la adultez temprana, con comportamientos agresivos posteriores. 
bine parámetros cuantitativos y cualitativos), es necesaria como base para iniciar una reflexión más profunda sobre sus efectos, pero no como único diagnóstico a tener en cuenta para proponer soluciones. Una simple mirada a las conclusiones de múltiples trabajos puede hacer comprobar resultados del todo contradictorios. La mayoría de los estudios parte de la base de que la televisión es un medio a través del cual el receptor adquiere modelos de conducta. En ese sentido hay que destacar dos grandes influencias: la teoría del aprendizaje social de Albert Bandura, según la cual el ser humano aprende nuevos comportamientos observando a otras personas o modelos, y la teoría del cultivo de George Gerbner, que relaciona los contenidos violentos en la televisión con las actitudes violentas en los individuos.

La Asociación Española de Usuarios de la Comunicación, en su dossier sobre La violencia en los medios de comunicación, señala varios factores que aparecen en las conclusiones de estos estudios:

- Ominipresencia de la violencia: en la evolución de la violencia televisiva, tanto en los programas de ficción como en los informativos, los documentales y los reality-shows.

- Impunidad de la violencia: la mayoría de los actos violentos mostrados en la pantalla quedan sin castigo, aun cuando los antagonistas principales de los relatos sí suelen recibir su merecido.

- Banalización de la violencia: en muchos casos la puesta en escena de la violencia televisiva es desdramatizadora, edulcorante, humorística, sin muestras o referencias al dolor de las víctimas o a los perjuicios físicos y emocionales que éstas padecen.

- Inevitabilidad de la violencia: la violencia aparece como el recurso más eficaz para la resolución de conflictos. De ahí que se ejerza por sistema tanto por los personajes negativos como por los protagonistas y personajes positivos del relato. La no utilización de la violencia se presenta casi siempre en términos de incapacidad.

En el otro extremo se sitúan las investigaciones que relativizan las afirmaciones anteriores. Consideran que la violencia está en la sociedad y no en la televisión. La televisión se limita a ofrecer, a dar forma a una situación que existe en la vida cotidiana, y sus efectos 
pueden ser o no ser negativos. Ferrés muestra dos de las tesis que sustentan esta teoría. Una es la tesis de la inhibición, según la cual las escenas violentas presentadas en la televisión tienen sobre el espectador efectos intimidadores que inhiben la manifestación de emociones y de conductas agresivas, sobre todo si el propio medio las reprueba. La segunda es la tesis de las catarsis, que afirma que las imágenes violentas permiten al espectador descargar sus tensiones y su agresividad. Cumplen una función de sustitución, de válvula de escape. La participación emotiva en la conducta agresiva mostrada permite renunciar a la propia agresividad ${ }^{15}$.

A partir de las interpretaciones anteriores, resulta fácil descubrir los enfoques teóricos que las sustentan, lo cual no impide reconocer la pertinencia de las constataciones de unos y otros. Lo que no puede hacerse es defenderlas desde una postura determinista que niega la posibilidad de diferentes opciones, y que en vez de responder a una situación compleja con el análisis, prefiere hacerlo con el axioma, es decir, considerando que su proposición es tan clara y evidente que se admite sin necesidad de demostración. Esa negación de la complejidad es uno de los peligros más serios a los que se enfrentan el sistema educativo y el mediático, y ha sido una constante tanto en la escuela como en los medios. Morin advierte que ante los problemas planteados por una sociedad en la que los fenómenos sociales están cada día más interrelacionados, cuando las acciones emprendidas para encontrar solución a un tema pueden provocar la aparición de problemas más graves que el que se pretende solucionar, la respuesta de la ciencia, de la política, de la economía (podemos añadir también de los medios y de la educación) es una: la simplificación. «La patología moderna del espíritu está en la hipersimplificación que ciega la complejidad de lo real. La patología de la idea está en el idealismo, en donde la idea oculta a la realidad que tiene por misión traducir, y se toma como única realidad. La enfermedad de la teoría está en el doctrinarismo y en el dogmatismo, que cierran a la teoría sobre ella misma y la petrifican. La patología de la razón es la racionalización, que encierra a lo real en un sistema de ideas coherente, pero parcial y unilateral, y que no sabe que una parte de lo real es irracionalizable, ni que la racionalidad tiene por misión dialogar con lo irracionalizable» 16 .

15 J. Ferrés (1994): Televisión y educación, Barcelona, Paidós, p. 119.

16 E. Mori Morin (1997): Introducción al pensamiento complejo, Barcelona, Gedisa, p. 34. 
Personalmente defiendo la postura de que no son los medios los que causan la violencia, sino, en todo caso, los que realizan un cierto tipo de representación de la violencia que ya existe en la sociedad y que se manifiesta en diversos contextos tanto públicos como privados. Ahora bien, esa representación no es inocente, y los medios deben asumir la responsabilidad de generar determinados tipos de contenidos que a veces ayudan, si no a la gestación, sí a la permanencia de actitudes violentas. Lo que pretendo es aportar un punto de vista que desplace la centralidad del debate desde los medios al concepto de conflicto. Propongo como base que la violencia es siempre el resultado de la no resolución de un conflicto, tanto individual. como social, y que, por lo tanto, tiene unas causas, un desarrollo, unas consecuencias y un contexto en el que se produce.

Si bien podemos considerar que la violencia en sí es negativa, el conflicto no lo es. En todo caso, lo que genera violencia es la incapacidad o la no voluntad de solucionarlo. El concepto de conflicto es fundamental para comprender el sentido de la existencia. Si bien la violencia puede ser evitable en una sociedad, el conflicto no lo es, y en su correcta resolución reside gran parte de lo que denominamos civilización.

En efecto, la teoría del conflicto nos enseña que su existencia es necesaria para que se produzca la evolución y el cambio tanto personal como social. La facultad de aprender, de adquirir progresivamente herramientas para saber vivir, está muy ligada a la facultad de saber enfrentarse a los sucesivos conflictos que plantea la existencia.

El conflicto social es uno de los ámbitos más estudiados por la Sociología, por la Psicología Social y por la Ciencia Política, y es uno de los elementos clave a la hora de construir los temarios periodísticos. A ese respecto Darhrendorf afirma: «El conflicto es un factor necesario en todos los procesos de cambio. Toda vida social es conflicto, porque es cambio. No hay en la sociedad humana algo estable, porque no hay nada cierto. En el conflicto, por lo tanto, se halla el núcleo generador de toda sociedad y la oportunidad de libertad, pero, al mismo tiempo, el reto para resolver racionalmente y controlar los problemas sociales» 17 .

Borrat, cuando analiza el periódico como actor de conflictos, cita a Meadow al afirmar que para que el conflicto exista (y se resuelva)

17 Citado por Héctor Borrat en El periódico, actor político (1983), Barcelona, Gustavo Gili, p.16. 
hacen falta el intercambio y la comunicación. En el mismo sentido menciona la teoría de Arno, que establece que el conflicto es creado, mantenido y resuelto mediante el intercambio de mensajes. La comunicación y el conflicto están, por tanto, íntimamente relacionados, y desde esta perspectiva la referencia a los medios de comunicación masiva se vuelve insoslayable.

\section{LA VIOLENCIA EN LAS INFORMACIONES PERIODÍSTICAS}

A pesar de que la televisión, por sus propias características, es el medio más cuestionado a la hora de establecer una relación con la violencia, no es el único. Podemos encontrar contenidos violentos en la prensa, en la radio, en el cine, en los videos, en los videojuegos o en Internet. Tanto en la ficción como en la no ficción cada uno de ellos puede mostrar la violencia y explicar el conflicto que la generó, o puede mostrar actos violentos aislados de su contexto o con una explicación insuficiente con el propósito de sesgar la información, o, simplemente, con el único fin de ofrecer un espectáculo y subir la sintonía ${ }^{18}$. En el primer caso, se están dando elementos para la comprensión del problema, lo que implica ofrecer a la audiencia una información con significado que le ayude a entender el mundo en el que vive y a formarse una opinión sobre él; en el segundo, se suministra una simple estimulación de los instintos primarios del espectador, que puede llevar a situaciones muy negativas.

En el ámbito del periodismo la inclusión de la violencia en los medios se justifica cuando ayuda a la información responsable, cuando hay una búsqueda de sentido. No se justifica cuando sólo busca espectáculo, favorecer el morbo, cuando omite los elementos para la reflexión y se queda en el mero estímulo y excitación del espectador. Sabemos que si se identifica el origen del conflicto es porque se lo está comprendiendo. En efecto, detrás de cada conflicto, tanto social como personal,

18 Utilizo aquí el término sintonía, en lugar de audiencia, de acuerdo con la diferenciación que establece Fuenzalida: «De manera general digamos que se entenderá el concepto de audiencias como las personas reales, los sujetos televidentes o receptores que entablan relaciones activas, contextos o mensajes de comunicación; desde el comienzo hablamos de audienciss para subrayar su diversidad. Por recepción entenderemos los procesos de relación de las audiencias con canales y mensajes. Por sintonía entenderemos la cifra cuantitativa de consumo, medida con el indicador el rating» (Televisión abierta y audiencia en América Latina, 2002, Buenos Aires, Grupo Editorial Norma, p. 38). 
hay una serie de necesidades insatisfechas, de problemas no resueltos, y su comprensión y conocimiento son de gran ayuda para su resolución. Por ello, ante un conflicto que se manifiesta con violencia los medios deben ofrecer una información en profundidad que explique -y no sólo describa- las razones que han provocado su eclosión. Esa explicación debe tener en cuenta las situaciones que han originado la violencia, y la perspectiva, las creencias, en definitiva, la cultura desde la cual se han originado esos hechos.

El reduccionismo o la simplificación son factores muy comunes en los medios a la hora de mostrar y de explicar la violencia, y sus consecuencias son muy claras: la distorsión de los hechos, la desinformación del receptor, y, por lo tanto, la dificultad de entender los procesos que se desarrollan en la sociedad y de adoptar determinadas posturas y acciones frente a ellos.

Hay que advertir, en cualquier caso, que un medio no es más responsable porque decida omitir contenidos violentos. En periodismo la ausencia de violencia no es siempre un buen síntoma. Es propio de regímenes totalitarios ocultar los conflictos internos que generan violencia, y hablar, en cambio, de situaciones violentas externas. La inclusión de la violencia (es decir, la narración de noticias que incluyen actos violentos) es necesaria cuando sirve para entender el significado del acontecer social. Si la violencia existe hay que hablar de ella. El problema es cómo hacerlo, ya que no es tanto lo que se dice sino cómo se dice.

\section{LA VIOLENCIA EN LOS CONTENIDOS DE LA FICCIÓN Y DEL ENTRETENIMIENTO}

Para analizar los contenidos violentos en los ámbitos de la ficción y del entretenimiento pueden aplicarse los mismos parámetros que en la no ficción. Pero es necesario añadir algunas reflexiones.

En la ficción, y sobre todo en los medios audiovisuales, el concepto de conflicto también es esencial. Ferrés afirma que hay que recurrir al conflicto (emotivo) para comprender los estímulos que producen los espectáculos audiovisuales, cinematográficos y televisivos. «El conflicto inherente a todo relato ofrece al inconsciente del espectador la posibilidad de activar los mecanismos psíquicos de la identificación y la proyección. El espectador tiene la oportunidad de vivir el conflicto como 
expresión metafórica de sus propios conflictos»19. Sin embargo, advierte de las distorsiones que se producen cuando sólo emplean el conflicto para el estímulo sensorial y emotivo del público, como ocurre en gran parte de los programas de televisión, o cuando se aprovecha con intención la potencialidad adormecedora de las emociones y su capacidad de bloquear la mente consciente, como ocurre con muchos mensajes publicitarios.

Más aún que en la no ficción, aquí es importante tener en cuenta la violencia explícita y la psicológica. Éstas se pueden encontrar no sólo en películas, sino, por ejemplo, en programas-concursos en los que se humilla al espectador, o se propician los enfrentamientos físicos y verbales de los concursantes o participantes como diversión del público. La falta de respeto al prójimo es un tipo de violencia que siempre es negativa y que está presente en muchas programaciones.

Con respecto a la violencia contenida en programas televisivos infantiles y juveniles, también hay que hacer algunas apreciaciones. No está comprobado que toda violencia en la pantalla sea mala para niños y jóvenes. Hay que ser cuidadosos sobre esto Hay un tipo de violencia que puede ayudarles a solucionar conflictos. Fuenzalida afirma que los niños y los jóvenes establecen una relación específica con el lenguaje audiovisual que tiene características lúdicas, de afectividad y de dramatismo. Un grupo importante de estos esquemas lúdico-dramáticos que están en la base de muchos programas televisivos contacta con motivaciones afectivas que tienen que ver con las necesidades de realización de si mismo, con el reconocimiento social y con la propia estima. Fuenzalida agrega que es importante intentar comprender las motivaciones que provocan la predilección por programas con contenidos violentos, por ejemplo en los dibujos animados. Considera que en este atractivo se combinan dos motivaciones: por una parte, la tendencia psicosomática a la acción inherente a la condición humana como condición de supervivencia; por otra, la necesidad psicológica de diferenciar claramente el Bien y el Mal. En ese sentido hay un tipo de programas que, a pesar de sus contenidos violentos, pueden constituir una forma lúdica y dramática de conocimiento y de aprendizaje afectivo20. dós, p. 97.

19 J. Ferrés (2000): Educar en la sociedad del espectáculo, Barcelona, Pai-

20 V. Fuenzalida (1999): Consumo y motivaciones del niño ante la televisión abierta, Santiago de Chile. Corporación de Promoción Universitaria. 
Existe una opinión compartida, basada en muchas investigaciones, que afirma la importancia de que los niños vean los programas de televisión en compañía de adultos para poder compartir significados y experiencias a partir de un análisis crítico. En ese sentido, tanto la mediación familiar como la escolar son fundamentales, y constituyen recursos muy eficaces a la hora de enfrentar posibles efectos negativos, como, por ejemplo, el impacto de escenas violentas. Sin embargo, el hecho de ver y de comentar la televisión en familia o en la escuela es importante, pero no basta. Es necesaria una mediación competente que haga posible que los niños puedan aprovechar al máximo las posibilidades que ofrece la televisión como acceso al conocimiento, al desarrollo y a la maduración de las emociones, y que evite o minimice los efectos adversos de determinados contenidos. En ese sentido las preguntas son: ¿están los padres, las familias, los profesores, preparados para ello? ¿Existe una alfabetización audiovisual al respecto? ¿Se encuentran indefensos ante una situación que les supera, y, debido a ello, muchas veces adoptan una postura bien pasiva bien defensiva ante los medios?

Opino que dar respuesta a las preguntas anteriores es mucho más perentorio que seguir realizando debates o investigaciones (tantas veces estériles) sobre los efectos perniciosos de la televisión. En tal aspecto, me parece más interesante una reflexión interdisciplinaria en torno a la relación entre la violencia y los medios que introduzca la complejidad que el tema requiere, y que lleve a la adopción de acciones comunes en el sistema educativo y en el mediático. Algunas de ellas pueden implicar el diseño de políticas de comunicación y de educación que ofrezcan programas de capacitación y alfabetización audiovisual para padres y profesores. 0 que los medios y los profesionales asuman su responsabilidad en este campo y respondan a códigos éticos en la oferta de sus contenidos.

\section{BIBLIOGRAFÍA}

AguAded, I. (1999): Convivir con la televisión. Familia, educación y recepción televisiva, Barcelona, Paidós.

BorRat, H. (1983): El periódico, actor político, Barcelona, Gustavo Gili.

Paidós.

CLAXTON, G. (2001): Aprender: El reto del aprendizaje continuo, Barcelona, 
CODINA, L. L. (2000): «El significado de la sociedad de la información en el seno de las autopistas de la información», en El libro digital y la www, Tauro Ediciones.

DÉLACÔTE, Goéry (2000): Enseñar y aprender con nuevos métodos. La revolución cultural de la era electrónica, Barcelona, Gedisa.

FERRÉS, J. (2000): Educar en una cultura del espectáculo, Barcelona, Paidós.

— (1994): Televisión y educación, Barcelona, Paidós.

FONTCUBERTA, M. de (2001): «Comunicación y educación: una relación necesaria», en Cuadernos de información, núm. 14, Facultad de Comunicaciones, Pontificia Universidad Católica de Chile, pp.140-147.

— (2000): «Medios, comunicación humana y sociedad del conocimiento», en Comunicar, núm.14, Huelva, p. 25.

— (2000): «¿De la tiza a Internet? Los desafíos de la educación en tiempos de nuevas tecnologías», en Desafíos de la sociedad de la información en América Latina y Europa, Primer Foro de las Comunicaciones, UNICOM.

- (2000): «Los medios, herramientas para aprender a vivir», en Apropiarse del diario. Enseñar y aprender los medios, Los Andes (Argentina), pp. 37-49.

- (1999): «Educación para la comunicación en la sociedad del conocimiento», en Televisión y niños. Ramón Florenzano Urzúa y Jorge Molina Valdivieso (eds.), Corporación de Promoción Universitaria y Televisión Nacional de Chile, Santiago, pp. 189-200.

- (1997): «El rol de los medios de comunicación ante un nuevo tipo de conocimiento», en Retos de la sociedad de la información. Estudios de comunicación en honor de la Dra. Maria Teresa Aubach, Publicaciones de la Pontificia Universidad de Salamanca, pp. 271-291.

FowLES, J. (1999): The Case for Television Violence, Londres, Nueva Delhi, Sage Publications Inc. International Educational and Professional Publisher Thousands Oaks.

FuenzalidA, V. (2002): Televisión abierta y audiencia en América Latina, Buenos Aires, Editorial Norma.

- (1999): «Consumo y motivaciones de los niños ante la televisión abierta», en Televisión y niños, Ramón Fiorenzano y Jorge Molina (eds), Corporación de Promoción Universitaria, Televisión Nacional de Chile.

KegAN, R. (1997): In Over our Heads: The Mental Demands of Modern Life. Cambridge Harvard University Press.

LINARD, M. (1991): «Médiation technique et médiation humaine», en La formation multimédia. Apprendre et former autrement, Collection IDATE, Synapse.

MARTín-BARBERo, J. (1998): «Heredando el futuro, pensar la educación desde la comunicación», en C\&E, Cultura y Educación, núm. 9, p. 17.

MARTínEZ DE TODA, J. (1998): Metodología evaluativa de la educación para Ios medios: su aplicación con un instrumento multidimensional, Roma, Pontificia Universidad Gregoriana. 
OLIVEIRA SOARES, Ismar de (1998): «A Gestão da comunicação no espaço educativo (ou os desafios da era da informação para o sistema educacional», ponencia presentada al I Congreso Internacional en Comunicación y Educación, São Paulo.

Pérez Tornero, J. M. (comp.) (2000): Comunicación y educación en la sociedad de la información, Barcelona, Paidós.

PIETTE, J. (2000): «La educación en medios de comunicación y las nuevas tecnologías en la escuela», en Comunicar, núm.14, pp.79-88.

Tecnos.

SÁnchez NoriegA, J. L. (1997): Crítica de la seducción mediática, Madrid,

TAPSCOTT, D. (1998): Creciendo en un entorno digital. La Generación Internet, Bogotá, McGraw-Hill Interamericana. Madrid, Alianza.

Terceiro, J. B. (1996): Sociedad digital. Del homo sapiens al homo digitalis, 